\title{
OPORTUNIDADES DE NEGOCIOS: APEC, COREA DEL SUR Y PERÚ
}

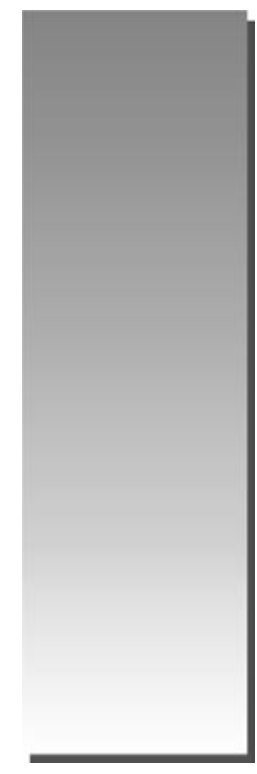

Pablo Mauricio Pachas*

E-mail:pwmauricio@yahoo.es

\section{RESUMEN}

El presente artículo trata sobre el comercio exterior de la economía coreana y su participación en el Foro de Cooperación Económica Asia -Pacífico (APEC), las exportaciones peruanas y las importaciones coreanas, así como los principales países de destino y origen, y principales productos comercializados por ambas economías.

Se destacan las oportunidades de comercio con el mercado de Corea del Sur y su relación con la oferta exportable actual de nuestro país, dentro del marco del Foro APEC.

Palabras clave: Foro de Cooperación Económica Asia-Pacífico (APEC), Perú, Corea del Sur, PBI, Balanza Comercial Perú-Corea.

\section{ABSTRACT}

The present article treats on the foreign trade of the Korean economy and its participation in the Asia Pacífic Economic Cooperation (APEC) Forum, the Peruvian exports and the Korean importings, as well as the main countries of destiny and origin, and main products marketed by both economies.

The opportunities of commerce with the market of South Korea they are emphasized and their relation with the current exportable offering of our country, inside the framework of the Forum APEC.

Key words: Asia Pacífic Economic Cooperation (APEC) Forum, Perú, South Korea, PBI, Trade balance Peru-Korea.

\footnotetext{
* Magíster en Economía (UNMSM). Economista. Pasantía en la Bolsa de Valores de New York (New York Stock Exchange - NYSE), Estados Unidos. Actualmente es Consultor de Negocios Bursátiles, Profesor Principal y Director de la Escuela de Negocios Internacionales (UNMSM), Profesor de Maestría en el área de Gestión y Finanzas.
} 


\section{MARCO GENERAL}

Actualmente la economía mundial mantiene un sólido crecimiento con la rápida expansión de las economías emergentes como China, junto a la mayor producción registrada en los países desarrollados, particularmente en Europa, que ha conllevado a una expansión de la demanda mundial de bienes y servicios, incluidos los mercados de materias primas, pese a la desaceleración de las principales economías como la de Estados Unidos, afectada por la crisis de la hipoteca subprime ${ }^{1}$. Sin embargo, los factores de riesgo tales como la inestabilidad de los mercados financieros mundiales y el aumento de las presiones inflacionarias derivadas del aumento del petróleo y precios de las materias primas, no han perjudicado el crecimiento de las economías emergentes, incluido nuestro país.

En la actualidad, el Perú es uno de los diez países con mayor crecimiento macroeconómico a nivel mundial, según fuentes del Fondo Monetario Internacional (FMI) en los años 2005-2006, destacando tanto por las oportunidades de inversión extranjera que ofrece como por el elevado nivel de crecimiento económico que viene registrando durante los últimos seis años (2002-2007) en que hemos pasado de $5.0 \%$ de crecimiento del PBI en el 2002, 6.7\% en el 2005 para luego alcanzar el $9.0 \%$ en el 2007 .

Los indicadores macroeconómicos en aumento indican importantes zonas de industrialización que se vienen generando como producto de una inversión colectiva, lo que se conoce como "fenómenos de crecimiento", en varios lugares del país, debido a que el Perú tiene una gran riqueza de recursos naturales.

La exportación es el régimen aduanero aplicable a las mercancías en libre circulación que salen del territorio aduanero para su uso o consumo definitivo en el exterior ${ }^{2}$. Las exportaciones peruanas registradas en la fecha de embarque son desagregadas en tradicionales y no tradicionales. Las primeras representan alrededor del $70 \%$ del total, mientras que las exportaciones no tradicionales alcanzan el $30 \%$ restante.

Las exportaciones tradicionales son los productos de exportación que históricamente han constituido la mayor parte del valor de nuestras exportaciones. En términos relativos, tienden a tener un valor agregado menor que el de los productos no tradicionales. Legalmente están definidos en la lista de exportaciones tradicionales del D. S. №076-92-EF; entre las que se considera a los siguientes productos: algodón, azúcar, café, harina y aceite de pescado, cobre, estaño, hierro, oro, plata, plomo, zinc, molibdeno, petróleo crudo y derivados, el rubro "resto de agrícolas" que comprende a la hoja de coca y derivados, melazas, lanas y pieles y el rubro "resto de mineros" que incluye al bismuto y tungsteno, principalmente.

Las exportaciones no tradicionales constituyen productos de exportación que tienen cierto grado de transformación o aumento de su valor agregado y que, históricamente, no se transaban con el exterior en montos significativos.

De acuerdo con la metodología de la balanza de pagos, a las exportaciones reportadas por la Superintendencia Nacional de Administración Tributaria (SUNAT) se agregan la venta de combustibles y alimentos a naves extranjeras y la reparación de bienes de capital, los cuales se agrupan dentro del rubro "Otros" de las exportaciones.

Desde la década de los cincuenta la economía de Corea del Sur ha venido creciendo rápidamente, convirtiéndose en la décimo primera economía más grande (por PBI nominal) en el mundo, describiendo un ritmo equilibrado de crecimiento en sus exportaciones y su demanda interna, encontrándose entre los países más avanzados tecnológicamente y mejor conectados digitalmente. Recientemente, el gobierno de Corea ha recibido una alta evaluación por parte de diversas organizaciones en todo el mundo, por lo que en sólo diez años se ha convertido en uno de los países con más alto rendimiento en el mundo en términos de tecnología de la información.

\section{El comercio con Corea del Sur}

En noviembre del 2003 los líderes de Asia Pacífico acordaron elegir al Perú como sede de la XVI Cumbre del Foro APEC a realizarse en el 2008, lo que representa un gran desafío para nuestro país ya que este evento permitirá acercar nuestra economía a los estándares de eficiencia y competi-

1 Un crédito subprime es una modalidad crediticia del mercado financiero de Estados Unidos que se caracteriza por tener un nivel de riesgo de impago superior a la media del resto de créditos (United States Department of Housing and Urban Development)

2 SUNAT ADUANAS: http://www.aduanet.gob.pe/aduanas/informag/exportac.htm 
Cuadro №1. Principales referencias de Perú y Corea del Sur

\begin{tabular}{|l|l|l|}
\hline \multicolumn{1}{|c|}{ Nombre oficial } & \multicolumn{1}{|c|}{ República del Perú } & \multicolumn{1}{c|}{ República de Corea del Sur } \\
\hline Área (km²) & 1 '285,215 $\mathrm{km}^{2}$ & $99,538.70 \mathrm{~km}^{2}$ \\
\hline Costas $\mathbf{( k m )}$ & $2,414 \mathrm{~km}^{2}$ & $2,413 \mathrm{~km}^{2}$ \\
\hline Puertos & $\begin{array}{l}\text { Callao, Chimbote, Ilo, Matarani, Paita, } \\
\text { Salaverry, San Martín. }\end{array}$ & $\begin{array}{l}\text { Chinhae, Inchon, Kunsan, Masan, } \\
\text { Mogpo, P'ohang, Pusán, Tonghae-hang, } \\
\text { Ulsan, Yosu. }\end{array}$ \\
\hline Límites marítimos & 200 millas (mar territorial). & $\begin{array}{l}12 \text { millas (mar territorial), 200 millas } \\
\text { (zona económica exclusiva). }\end{array}$ \\
\hline División política & $\begin{array}{l}\text { 24 departamentos y 1 provincia con- } \\
\text { stitucional (Callao). }\end{array}$ & $\begin{array}{l}9 \text { provincias (subdivididas, a su vez, en } \\
137 \text { distritos). }\end{array}$ \\
\hline Capital & $\begin{array}{l}\text { Lima (fundada el 18 de enero de1535 } \\
\text { por Francisco Pizarro). }\end{array}$ & Seúl (fundada en 1394) \\
\hline Unidad monetaria & Nuevo Sol. & Won Surcoreano. \\
\hline Idiomas & $\begin{array}{l}\text { Oficiales: español y quechua; no } \\
\text { oficiales: aymara y otras lenguas in- } \\
\text { dígenas. }\end{array}$ & Oficial: coreano; no oficiales: chino \\
\hline Fiesta nacional & 28 de julio, Día de la Independencia. & 15 de agosto, Liberación. \\
\hline Gentilicio & Peruano. & Surcoreano \\
\hline Hora oficial & GMT -5 horas (normal), -4 (verano). & GMT +9 horas (normal), +10 (verano). \\
\hline Miembro de & $\begin{array}{l}\text { ONU, OEA, ANSA, APEC, ALADI, CSN, } \\
\text { CAN, MERCOSUR, BID, Grupo de Río, } \\
\text { FLAR, CAF, CIN, OEI. }\end{array}$ & \\
\hline
\end{tabular}

tividad de las economías de Asia-Pacífico. También será una oportunidad para difundir, a nivel mundial, los diversos atractivos que nuestro país posee y desarrollar la promoción de oportunidades de negocios y de inversión entre los miembros del Foro. Es por ello que el presente estudio centra su atención en identificar las oportunidades de negocios con alto grado de rentabilidad entre Perú y Corea del Sur, desde la perspectiva del comercio internacional.

En esta dirección, las oportunidades de negocio estarán directamente vinculadas a los principales productos exportables de la economía peruana, así como a los principales productos importados por Corea del Sur con respecto al resto del mundo y a ambos países, respectivamente. Como premisa establecemos "la existencia de un nicho de mercado en Corea de Sur y su relación con la capacidad de la oferta exportable del Perú" en el marco del Foro de Cooperación Económica Asia-Pacífico (APEC), siendo necesario determinar los principales productos importados por Corea del Sur para luego relacionarlos con los principales productos que podrían comercializarse entre ambos países y así establecer la ventaja comparativa ${ }^{3}$ (ver Cuadro №1).
Gráfico № 1. Mapa del Perú.

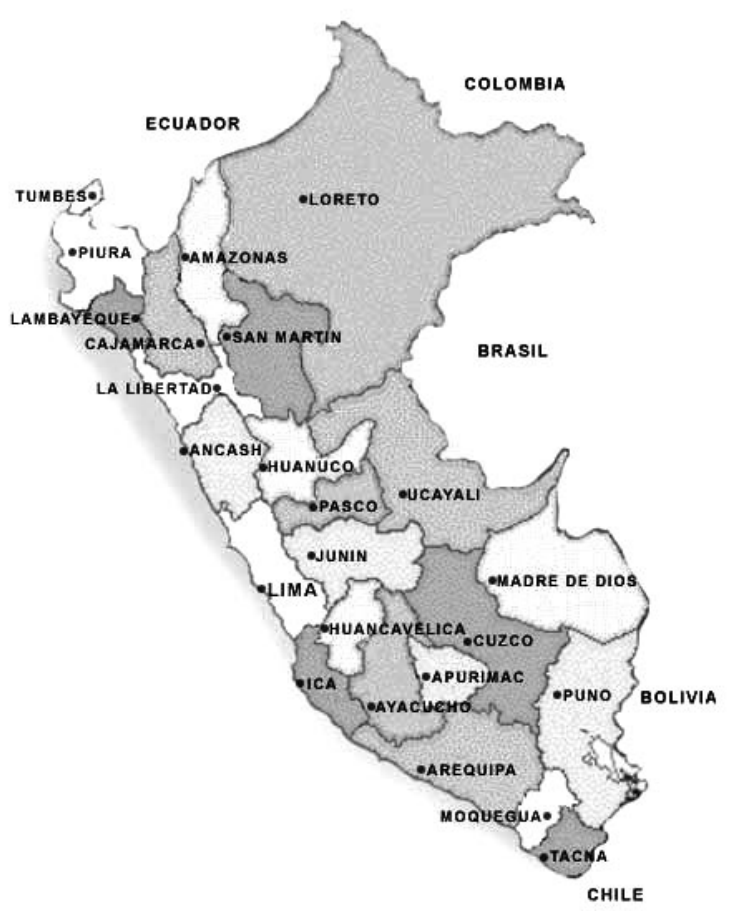

El Perú es un país situado en el lado occidental de la zona de Sudamérica, comprendida entre la línea ecuatorial y el Trópico de Capricornio (ver Gráfico № 1). Limita por el norte con Ecuador y

3 Ventaja comparativa: situación en la que un país puede producir un bien a un costo total menor con respecto a otro país. 
Gráfico №2. Mapa de Corea del Sur.

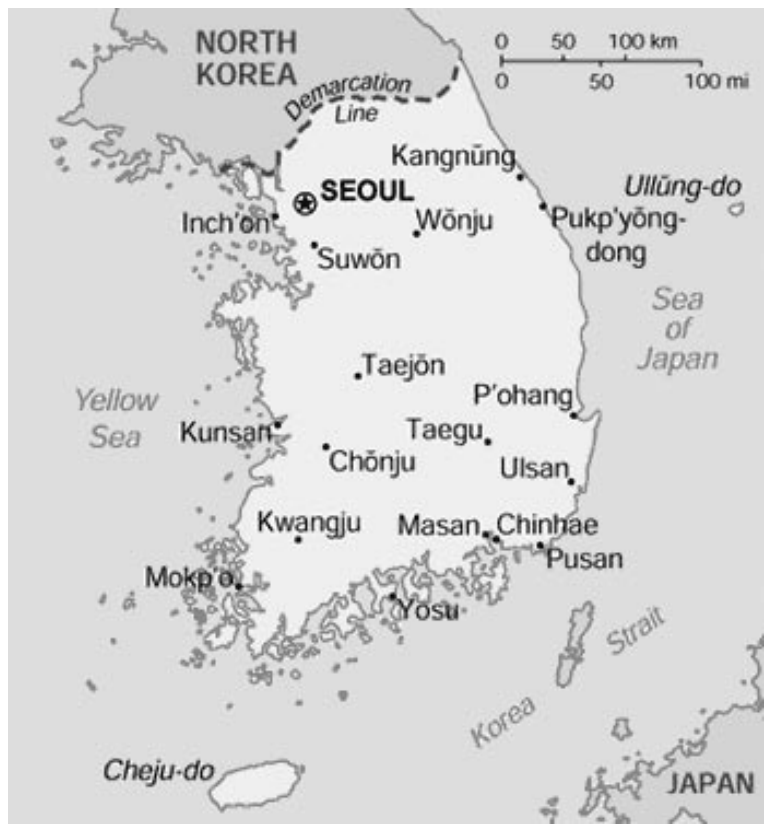

Colombia, por el este con Brasil, por el sureste con Bolivia, por el sur con Chile y por el oeste con el Océano Pacífico. El territorio peruano presenta tres regiones definidas: la costa, sierra (región andina) y la selva o amazónica. Las principales ciudades son las capitales de departamentos, destacando las ciudades de Lima, Arequipa, Trujillo, Chimbote, Chiclayo, Piura y la provincia constitucional del Callao (en la costa), Cuzco e Iquitos en la sierra y selva, respectivamente.

La República de Corea del Sur, comúnmente conocida como Corea del Sur, es un país de Asia oriental, ubicado en la parte Sur de la Península de Corea (ver Gráfico № 2). Limita al norte con la República Democrática Popular de Corea (o Corea del Norte), con la cual formaba un solo país hasta 1945; al Este con el Mar del Japón, al Sureste y Sur con el estrecho de Corea que lo separa de Japón, y al oeste con el mar Amarillo. Las principales ciudades son Seúl, Pusán, Taegu, Inchon y Taejon.

El Foro de Cooperación Económica AsiaPacífico (APEC) y Perú, reúne a las economías más importantes y dinámicas del Asia-Pacífico. Sus miembros constituyen un porcentaje elevado de la población mundial, y en conjunto constituyen los mayores porcentajes de comercio internacional y PBI global. Además, la Cuenca del Pacífico es la región para la cual se proyecta el mayor crecimiento económico en este milenio, por lo que participar en APEC implica estrechar aún más los vínculos con sus demás miembros.
Nuestro país tiene una gran ventaja al participar en este foro, ya que es el único miembro de la Comunidad Andina en APEC y, por otro lado, desde el punto de vista geográfico, el Perú está muy bien ubicado para convertirse en el puente (hub) del flujo comercial entre Asia y Sudamérica.

APEC también es una plataforma para impulsar acuerdos de relaciones económicas internacionales, posibilitando que nuestro país se convierta en un socio estratégico de Asia y Oceanía dentro de América Latina. APEC es el principal socio comercial del Perú en el mundo. En el 2006 el intercambio comercial con las economías de APEC ascendió a US\$ 38,757 millones aproximadamente, equivalente al $55 \%$ del comercio total peruano. (Ver Gráfico №3).

En los últimos años, el comercio del Perú con APEC se ha expandido significativamente. Entre los años 2000 y 2006, las exportaciones hacia APEC aumentaron en $270 \%$, al pasar de US\$ 3,709.3 a US\$ 13,635.5 millones. Asimismo, las importaciones procedentes de APEC se incrementaron en $90 \%$, de US\$ 3,892.5 a US\$ 7,400.2 millones.

Con relación al aspecto macroeconómico peruano, cuyo desempeño actual es de elevado crecimiento, destacaremos la serie histórica del PBI durante 1992-2008 que nos permite observar un comportamiento positivo, con acumulación de períodos consecutivos de crecimiento económico, donde se hace evidente que la economía peruana viene atravesando por una fase expansiva.

El fuerte crecimiento observado se desarrolló en un clima de alto nivel de confianza por parte de empresarios y consumidores, favorecido por un entorno macroeconómico con estabilidad de precios, una posición fiscal superavitaria, un mayor dinamismo del crédito y un escenario internacional con tasas altas de crecimiento y elevados

Gráfico №3. Intercambio Comercial Perú Mundo 2006 Total US\$ 38,757 millones.

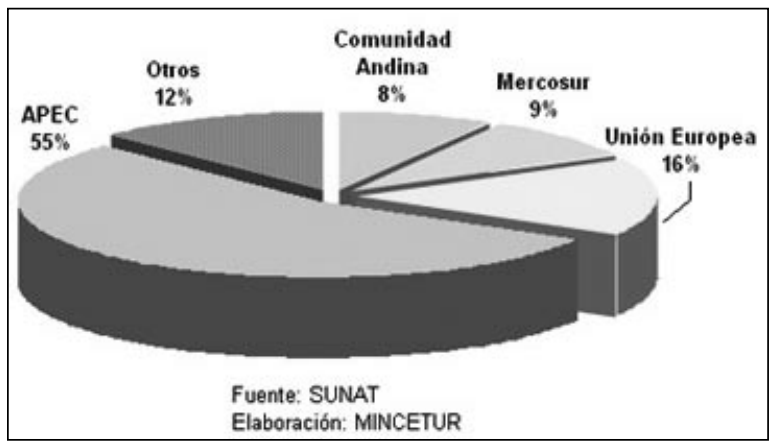


precios de nuestros principales productos de exportación, como los minerales (el mayor incremento de los términos de intercambio en los últimos 56 años). Este crecimiento estuvo asociado a una mejora de la productividad de los factores de producción y a mayores niveles de inversión que tuvieron un impacto positivo sobre el crecimiento del producto potencial. La mayor productividad se debió a la renovación y ampliación de maquinarias y equipos, al incremento del empleo formal, al acceso a nuevos mercados de exportación y a un mejor ambiente de negocios.

El desempeño favorable de la economía es explicado por el incremento de la demanda interna y externa, evidenciada en un mayor consumo e inversión privada y pública, que se traducen en mayores proyectos de inversión en el sector electricidad, comunicaciones, hidrocarburos, minero (con el inicio de operaciones de empresas y unidades mineras nuevas), edificación de viviendas, centros comerciales, así como, el avance de importantes obras de infraestructura vial. Con relación a la demanda externa, las exportaciones registraron en el año una cifra récord, situándose en US\$ 27,588.27 millones, logrando un incremento en términos reales de $4.82 \%$, destacando entre los productos tradicionales como los productos mineros (cobre, zinc, plomo y oro); así también entre los productos no tradicionales figuran los productos textiles, agroindustriales, químicos, siderometalúrgicos y pesqueros, favorecidos por los mejores precios en el mercado internacional, el crecimiento de los países de Asia, la prórroga de la Ley de Promoción Comercial Andina y Erradicación de la Droga (APTDEA), y el desarrollo favorable de las economías de los países de la región y de nuestros principales socios comerciales (ver Gráfico № 5).

A lo largo de estos últimos años, la actividad económica peruana ha tenido tasas elevadas y crecientes, pasando de una tasa de crecimiento de $5.2 \%$ en 2004 a $6.74 \%$ en 2005, y una expansión de $8.0 \%$ en el $2006^{4}$. Para el año 2007 la producción nacional o PBI alcanzó un crecimiento de $8.99 \%$ respecto al año 2006, registrando la tasa más alta después de trece años, con lo que se consolida la expansión de la economía por nueve años seguidos, sustentado en el crecimiento de todos los sectores productivos ${ }^{5}$. En enero del 2008, la economía peruana ha registrado un crecimiento
Gráfico №4. Producto Bruto Interno 1992-2008 (Variación \% Anual).

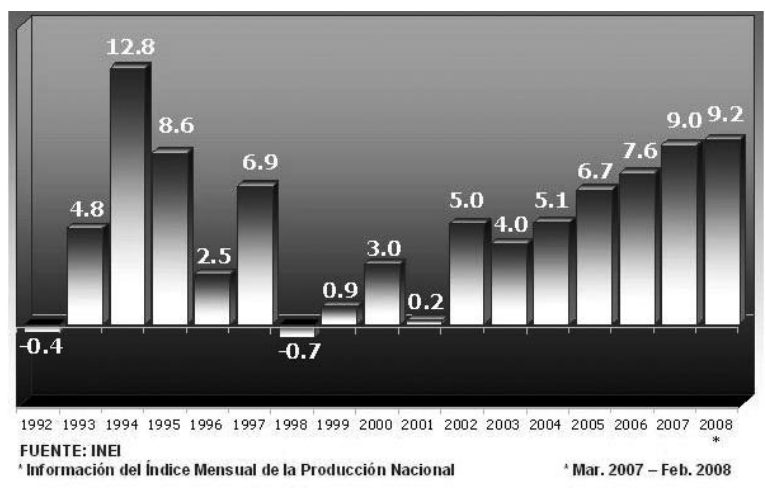

del 9\% impulsada por los sectores Construcción (21.6\%), minería e hidrocarburos (13.5\%) y por el subsector manufactura no primaria $(9.8 \%)$, anunció el Banco Central de Reserva (BCRP) ${ }^{6}$.

Por su parte, el sector Minería e Hidrocarburos habría crecido $13.5 \%$ debido a la mayor producción de cobre (impulsada por la Sociedad Minera Cerro Verde) y la mayor producción de oro bajo el supuesto que Barrick y Yanacocha mantengan el ritmo de su producción acorde con los meses anteriores, pero esta mayor producción se habría visto atenuada por la menor producción de plomo, indicó el BCRP. En el 2006, la producción conjunta de los sectores no primarios creció 9,3\%, tasa superior a la del PBI, en un contexto de mayor dinamismo en la expansión de la demanda interna. De acuerdo a información de 158 empresas, la manufactura no primaria habría crecido $9.8 \%$ principalmente por una mayor producción de alimentos y bebidas; minerales no metálicos; productos metálicos; productos químicos, caucho y plásticos; la industria del hierro y acero; y, la industria del papel e imprenta de acuerdo con sus proyecciones

Gráfico № 5. Evolución mensual de la Producción Nacional 2005-2007 (variación \% respecto a similar mes del año anterior).

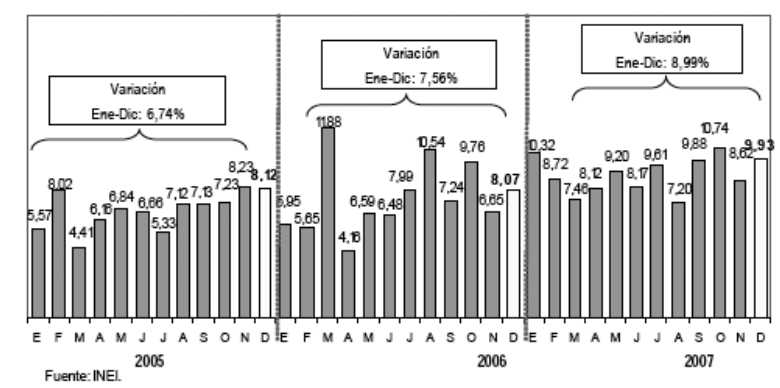

4 Banco Central de Reserva del Perú (BCRP). Memoria Anual 2006. http://www.bcrp.gob.pe

5 Banco Central de Reserva del Perú (BCRP). Memoria Anual 2006. http://www.bcrp.gob.pe

6 Diario El Comercio. 24 de Febrero 2008. http://www.elcomercioperu.com.pe/ 
de demanda. El sector construcción habría tenido un repunte de $21.6 \%$, de acuerdo a información de consumo interno de cemento de diciembre, que aumentó $20 \%$. Al 14 de febrero la producción del subsector electricidad, reportada por el Comité de Operación Económica del Sistema Interconectado Nacional (COES-Sinac), muestra un incremento de $10.1 \%$ con respecto al mismo mes de 2007 , y en enero del 2008 el incremento fue de $9 \%$.

En los últimos años la apertura comercial de la economía peruana ha alcanzado niveles sin precedentes del 39\% del PBI en términos reales (suma de exportaciones e importaciones de bienes y servicios), al incrementar el nivel de competencia que deben enfrentar las empresas locales, ha aumentado la necesidad y los incentivos para ganar competitividad en un número creciente de empresas $^{7}$. Esta apertura es más notoria en los últimos años, habiendo pasado de $30 \%$ a inicios de los noventa a $43 \%$ como promedio entre 2004 y 2006 , lo cual es un factor importante tras el incremento observado en la productividad de la economía (ver Gráfico № 6).
En los años 2006 y 2007 las exportaciones FOB anuales se han incrementado en un $15.9 \%$ mientras que para el mismo período en las importaciones CIF anuales también se ha notado un aumento de $33.6 \%$ con lo cual, en diciembre de 2007, el intercambio comercial peruano se expandió en $12.2 \%$ respecto al mismo mes del año anterior, alcanzando la cifra de US\$ 4,627.4 millones, lo cual llevó a un acumulado en el 2007 de US\$ 48,035 millones, presentándose un incremento del $22.8 \%$ con respecto al año anterior.

Por su parte, en diciembre de 2007, el saldo comercial peruano llegó a US\$ 861.2 millones con una disminución en la variación con respecto al mismo mes del año anterior en $27.9 \%$, mientras que en el acumulado del 2007 alcanzó US\$ 7,143.3 millones, disminuyendo en $15.9 \%$ con respecto al año 2006 (ver Cuadro № 2).

Los cinco principales países con los cuales el Perú presentó un superávit comercial en el 2007 fueron Chile,Japón, Canadá, Estados Unidos y Suiza; por el contrario, se obtuvo déficit comercial con Colombia, México, Brasil, Argentina y Ecuador (ver Gráfico N. 7).

Gráfico N. 6. Apertura comercial (exportaciones más importaciones como porcentaje del PBI real)

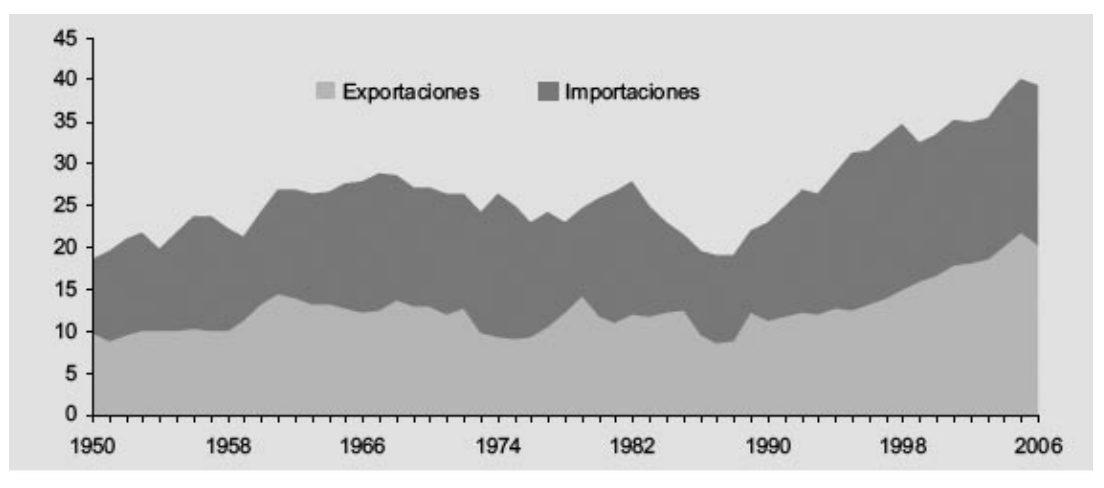

Cuadro № 2. Saldo e Intercambio Comercial (Millones de US\$).

\begin{tabular}{lrrrrrl}
\hline & \multicolumn{3}{c}{ Diciembre } & \multicolumn{3}{c}{ Enero - Diciembre } \\
\cline { 2 - 7 } & 2006 & \multicolumn{1}{c}{2007} & \multicolumn{1}{c}{ Var. \% } & \multicolumn{1}{c}{ 2006 } & 2007 & Var. \% \\
\hline Exportaciones FOB & 2659.1 & 2744.3 & 3.2 & 23799.6 & 27589.1 & 15.9 \\
Importaciones CIF & 1464.3 & 183.1 & 28.6 & 15308.2 & 20445.9 & 33.6 \\
Saldo Comercial & 1194.8 & 861.2 & -27.9 & 8491.5 & 7143.3 & -15.9 \\
Intercambio comercial & 4123.4 & 4627.4 & 12.2 & 30107.8 & 48035 & 22.8
\end{tabular}

1/El concepto de Saldo Comercial considera el valor de los bienes en el mismo lugar físico, por lo que resulta de exportaciones FOB menos importaciones CIF. Este concepto difiere de lo que se considera como Balanza Comercial.

Fuente: SUNAT.

Elaboración: MINCETUR

7 Banco Central de Reserva del Perú (BCRP); Memoria Anual 2006; http://www.bcrp.gob.pe 
Gráfico N.o 7. Saldo Comercial - Principales Socios: Ene-Dic 2007 (Millones de US\$)

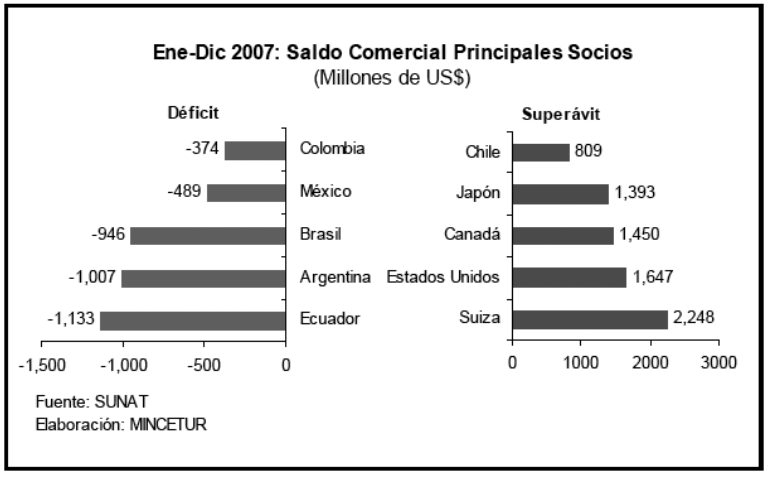

\section{BALANZA COMERCIAL PERUANA SUPERAVITARIA IMPULSA EL CRECIMIENTO, DESDE EL 2002}

Los elevados niveles de precios que mantuvieron nuestras materias primas como los minerales en los mercados internacionales durante los últimos cinco años y los mayores volúmenes de exportación de productos no tradicionales, fueron factores fundamentales para que la balanza comercial peruana registre un superávit comercial a partir del 2002 y se obtenga el récord de US\$ 8,934 millones en el año 2006, mayor en US\$ 3,648 millones con respecto al registrado el año
Gráfico N.o 8. Balanza comercial (Millones de US\$)

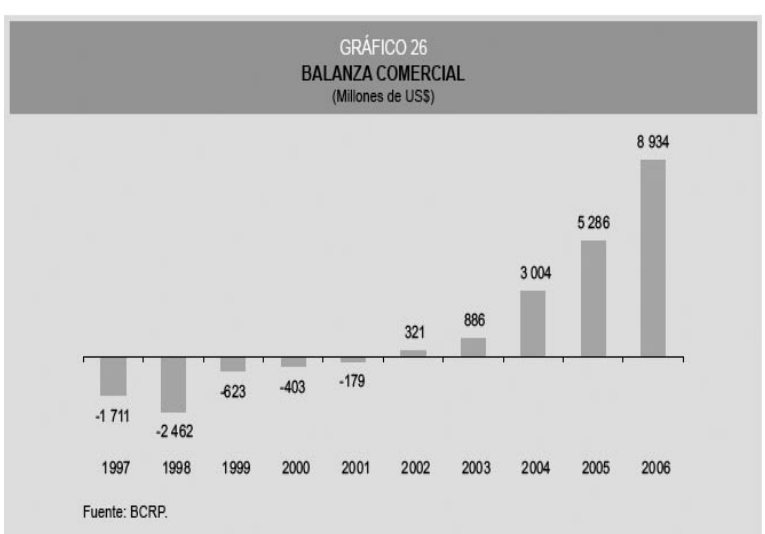

anterior, el cual fue equivalente a 9,6\% del PBI, alcanzando un récord histórico, con una leve disminución en el año 2007 en que la balanza comercial registró \$8,368 millones, cantidad menor a la del 2006, debido a la crisis de la economía internacional (ver Gráfico № 8).

En diciembre del 2007 las exportaciones reales FOB peruanas se expandieron en $13.1 \%$, ante el dinamismo en los volúmenes exportados de oro, cobre y harina de pescado. En diciembre del 2007 el valor real de las exportaciones alcanzó los US\$ 1,202.8 millones, superior en US\$ 139.5 millones

Cuadro № 3. Exportaciones por sectores económicos.

\begin{tabular}{|l|r|r|r|r|r|r|}
\hline & \multicolumn{4}{|c|}{ Diciembre del 2007} & \multicolumn{2}{c|}{ Enero - Diciembre 2007 } \\
\hline & \multicolumn{1}{|c|}{$\mathbf{2 0 0 6}$} & \multicolumn{1}{c|}{$\mathbf{2 0 0 7}$} & \multicolumn{1}{c|}{ Var. \% } & \multicolumn{1}{c|}{$\mathbf{2 0 0 6}$} & \multicolumn{1}{c|}{$\mathbf{2 0 0 7}$} & \multicolumn{1}{c|}{ Var. \% } \\
\hline Minería y petróleo & $1,882.7$ & -0.3 & 68.6 & $19,379.3$ & 16.7 & 70.2 \\
\hline Pesquero & 156.5 & -0.6 & 5.7 & $1,958.7$ & 10.4 & 7.1 \\
\hline Textil & 214.9 & 71.3 & 7.8 & $1,729.8$ & 17.5 & 6.3 \\
\hline Agropecuario & 237.5 & 14.8 & 8.7 & $1,963.9$ & 9.5 & 7.1 \\
\hline Químico & 81.3 & 52.8 & 3.0 & 798.1 & 33.4 & 2.9 \\
\hline Sidero-Metalúrgico & 72.3 & -2.7 & 2.6 & 802.7 & 11.9 & 2.9 \\
\hline Maderas y papeles & 37.3 & 41.6 & 1.4 & 359.3 & 8.1 & 1.3 \\
\hline Metal-mecánico & 21.5 & 62.6 & 0.8 & 215.1 & 31.1 & 0.8 \\
\hline Minería no metálica & 17.5 & 85.8 & 0.6 & 164.6 & 21.8 & 0.6 \\
\hline Pieles y cueros & 4.0 & 45.3 & 0.1 & 39.3 & 15.2 & 0.1 \\
\hline $\begin{array}{l}\text { Varios (inc. joyería y algunos } \\
\text { productos hechos a mano) }\end{array}$ & 18.8 & 46.6 & 0.7 & 178.3 & 4.0 & 0.6 \\
\hline TOTAL & $2,744.3$ & 6.8 & 100.0 & $27,589.1$ & 15.9 & 100.0 \\
\hline Tradicional & $2,041.3$ & -1.2 & 74.4 & $21,296.2$ & 15.0 & 77.2 \\
\hline No tradicional & 703.0 & 39.6 & 25.6 & $6,292.9$ & 19.1 & 22.8 \\
\hline TOTAL & $2,744.3$ & 6.8 & 100.0 & $27,589.1$ & 15.9 & 100.0 \\
\hline
\end{tabular}

Fuente: SUNAT. Elaboración MINCETUR. 
Cuadro № 4. Exportaciones del Perú por Bloque Económico (Ene-Abr 2007 / 2006) (millones de dólares)

\begin{tabular}{|c|c|c|c|c|}
\hline PAÍS & ENE - ABR 2006 & ENE - ABR 2007 & $\begin{array}{c}\text { VAR. \% 2007 / } \\
2006\end{array}$ & CONTRIB. \% 2007 \\
\hline NAFTA & $2,423.6$ & $2,034.1$ & $-16.1 \%$ & $26.8 \%$ \\
\hline Estados Unidos & 1833.7 & 1438.5 & $-21.6 \%$ & $18.9 \%$ \\
\hline Canadá & 521.8 & 496.3 & $-4.9 \%$ & $6.5 \%$ \\
\hline México & 68.1 & 99.3 & $45.9 \%$ & $1.3 \%$ \\
\hline UNIÓN EUROPEA & 971.5 & 1210.8 & $24.6 \%$ & $15.9 \%$ \\
\hline España & 183.4 & 258.6 & $41.0 \%$ & $3.4 \%$ \\
\hline Italia & 179.4 & 243.3 & $35.6 \%$ & $3.2 \%$ \\
\hline Alemania & 176.3 & 231.8 & $31.5 \%$ & $3.1 \%$ \\
\hline Países Bajos & 162.5 & 143.7 & $-11.6 \%$ & $1.9 \%$ \\
\hline Bélgica & 54.7 & 110.6 & $102.1 \%$ & $1.5 \%$ \\
\hline Francia & 46.0 & 56.9 & $23.6 \%$ & $0.7 \%$ \\
\hline Reino Unido & 89.6 & 47.8 & $-46.7 \%$ & $0.6 \%$ \\
\hline Finlandia & 27.2 & 43.6 & $60.4 \%$ & $0.6 \%$ \\
\hline Suecia & 24.2 & 21.7 & $-10.2 \%$ & $0.3 \%$ \\
\hline Dinamarca & 12.1 & 19.2 & $58.7 \%$ & $0.3 \%$ \\
\hline Portugal & 8.1 & 15.2 & $87.7 \%$ & $0.2 \%$ \\
\hline Grecia & 2.0 & 8.0 & $295.9 \%$ & $0.1 \%$ \\
\hline Polonia & 2.1 & 4.2 & $97.9 \%$ & $0.1 \%$ \\
\hline Irlanda (Eire) & 0.9 & 1.5 & $74.4 \%$ & $0.0 \%$ \\
\hline Eslovenia & 0.2 & 1.2 & $505.8 \%$ & $0.0 \%$ \\
\hline República Checa & 0.7 & 1.1 & $48.8 \%$ & $0.0 \%$ \\
\hline Lituania & 0.6 & 1.1 & $70.3 \%$ & $0.0 \%$ \\
\hline Estonia & 0.4 & 0.6 & $65.4 \%$ & $0.0 \%$ \\
\hline Hungría & 0.6 & 0.4 & $-23.0 \%$ & $0.0 \%$ \\
\hline Austria & 0.4 & 0.2 & $-37.7 \%$ & $0.0 \%$ \\
\hline Chipre & 0.1 & 0.1 & $21.6 \%$ & $0.0 \%$ \\
\hline Letonia & 0.1 & 0.0 & $-12.5 \%$ & $0.0 \%$ \\
\hline Luxemburgo & 0.0 & 0.0 & $57.1 \%$ & $0.0 \%$ \\
\hline Malta & 0.0 & 0.0 & $-97.7 \%$ & $0.0 \%$ \\
\hline Eslovaquia & 0.0 & 0.0 & $-100.0 \%$ & $0.0 \%$ \\
\hline ASIA & $1,202.0$ & $1,998.7$ & $66.3 \%$ & $26.3 \%$ \\
\hline China & 582.3 & 1006.0 & $72.8 \%$ & $13.2 \%$ \\
\hline Japón & 263.8 & 513.5 & $94.7 \%$ & $6.8 \%$ \\
\hline Corea del Sur & 157.4 & 285.0 & $81.0 \%$ & $3.8 \%$ \\
\hline Taiwán & 115.4 & 91.8 & $-20.5 \%$ & $1.2 \%$ \\
\hline Hong Kong & 14.7 & 18.7 & $26.5 \%$ & $0.2 \%$ \\
\hline Otros Asia & 68.4 & 83.7 & $22.4 \%$ & $1.1 \%$ \\
\hline CAN & 391.3 & 506.7 & $29.5 \%$ & $6.7 \%$ \\
\hline Colombia & 138.3 & 180.5 & $30.6 \%$ & $2.4 \%$ \\
\hline Venezuela & 99.1 & 154.9 & $56.3 \%$ & $2.0 \%$ \\
\hline Ecuador & 101.0 & 106.3 & $5.2 \%$ & $1.4 \%$ \\
\hline Bolivia & 53.0 & 65.0 & $22.7 \%$ & $0.9 \%$ \\
\hline MERCOSUR & 222.3 & 293.6 & $32.1 \%$ & $3.9 \%$ \\
\hline Brasil & 198.4 & 261.7 & $31.9 \%$ & $3.4 \%$ \\
\hline Argentina & 21.2 & 28.3 & $33.6 \%$ & $0.4 \%$ \\
\hline Uruguay & 2.4 & 3.4 & $37.5 \%$ & $0.0 \%$ \\
\hline Paraguay & 0.2 & 0.2 & $2.5 \%$ & $0.0 \%$ \\
\hline OTROS MERCADOS & 805.8 & 1179.3 & $46.4 \%$ & $15.5 \%$ \\
\hline RESTO DE MERCADOS & 427.0 & 369.5 & $-13.5 \%$ & $4.9 \%$ \\
\hline EXPORTACIÓN TOTAL & $6,443.5$ & $7,592.8$ & $17.8 \%$ & $100.0 \%$ \\
\hline
\end{tabular}

Fuente: SUNAT

Elaboracion: PROMPEX 
$(13,1 \%)$ respecto al valor alcanzado en diciembre del 2006, explicado por los mayores volúmenes exportados de productos tradicionales entre los que destacan el oro, cobre refinado, harina de pescado en tanto que, entre los productos no tradicionales, figuran los mangos, mangostanes y los espárragos, principalmente.

En diciembre del 2007 las exportaciones se expandieron en $6.8 \%$ con respecto al mismo mes del año anterior, alcanzando US\$ 2,744.3 millones; mientras que en el año 2007, las exportaciones totales experimentaron una expansión de 15.9\% respecto al 2006, situándose en US\$27,589.1 millones (exportaciones por sectores económicos).

Durante el 2007 las exportaciones de productos tradicionales tuvieron un incremento del $15 \%$, mientras que las exportaciones de productos no tradicionales se incrementaron en $19.1 \%$, y las primeras representan el $77.2 \%$ del flujo total. A nivel sectorial cabe destacar el crecimiento de las exportaciones en todos los sectores, siendo los de mayor crecimiento el químico (33.4\%), metalmecánico (31.1\%), minería no metálica $(21.8 \%)$; además de minería y petróleo que siendo el sector con la mayor participación $(70.2 \%)$, tuvo un crecimiento de $16.7 \%$ (ver Cuadro N..$^{\circ}$ ).

Las exportaciones en el 2007 se dirigieron a 178 mercados de destino. Los principales destinos fueron: Estados Unidos (19.9\%), la Unión Europea (16.5\%), China (10.2\%), Suiza (9.0\%) y Japón (8.0\%). Asimismo los mercados más dinámicos, según su crecimiento acumulado, fueron Australia (155,6\%), India (105.3\%), Venezuela (84.3\%) y Japón (77.8\%). Cabe destacar que se incrementó en 464 el número de productos exportados, contándose con un total de 4,750. Asimismo, el número de empresas exportadoras pasó de 6,510 a 6,658; de estas empresas, el $64.0 \%$ realizó ventas al exterior por montos menores o iguales a US\$ $100 \mathrm{mil}$ (ver Cuadro N. ${ }^{\circ}$ ).

Los principales países de destino de nuestras exportaciones fueron Estados Unidos con 21.7\%; Suiza, 8.6\%; China, 8.3\%, Canadá, 6.8\%, Japón 5.0\% y Chile $4.5 \%$ del valor total de las exportaciones. Estados Unidos de América representa el principal mercado para nuestras exportaciones a pesar de la caída que presenta (-14.4\%); el segundo país de destino fue Suiza, al incrementar su valor de exportación en $20.7 \%$ ante el aumento en los volúmenes embarcados de oro, principal producto demandado por este país (ver Gráfico N. ${ }^{\circ}$ 9).
Gráfico N.o 9. Exportaciones reales, según destino. (millones de US\$ del 2002)

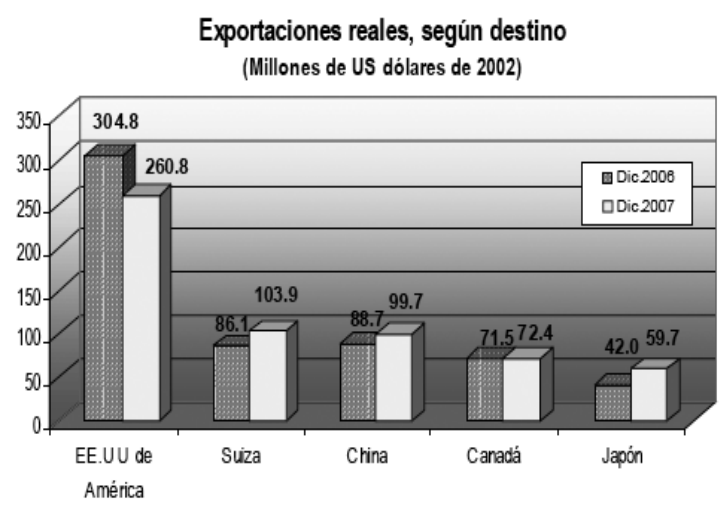

Entre los principales productos que se exportan figuran el oro, cátodos y secciones de cátodos de cobre refinado, los demás aceites pesados o fueloils, espárragos frescos o refrigerados, polos de algodón para hombre o mujer y plata sin alear. Según el producto (ver Cuadro № 5), el oro constituye el principal producto más comercializado en el mercado internacional; le siguen minerales de cobre y sus concentrados (19.5\%), harina de pescado sin desgrasar (17.2\%) y mangos y mangostanes (111.2\%).

\section{Con respecto a la producción y consumo de Corea del Sur:}

El ritmo de crecimiento del consumo privado de la economía coreana (PBI preliminar) aumentó a $4.7 \%$ en el tercer trimestre del 2007 , superando el $4.2 \%$ de crecimiento obtenido en el trimestre anterior.

Las ventas de bienes de consumo experimentaron un crecimiento ligeramente más lento de $5.9 \%$ en noviembre, ya que en octubre fue de $8.4 \%$; sin embargo, se mantiene la tendencia de aumento, no obstante que las ventas de los bienes duraderos (incluida ventas de automóviles) descendieron en $-3.4 \%$ entre otros factores debido a los altos precios del petróleo, luego de haber alcanzado $21.9 \%$, mientras que los bienes no duraderos de consumo creció en $1.1 \%$ en noviembre. La reciente recuperación en el consumo se considera sostenible ya que es apoyada por la aplicación de políticas de medio ambiente, incluida la mejora de los ingresos reales superior a la tasa de crecimiento del PBI (ver Cuadro N. ${ }^{\circ} 6$ ).

\section{Apertura Comercial Coreana}

Se puede apreciar que en las exportaciones e importaciones representó un $71 \%$ sobre el PBI 
en cifras de 2006, lo que ilustra el considerable grado de apertura comercial de la economía coreana y, al mismo tiempo, su fuerte dependencia del exterior. El total de importaciones (CIF) representó en el 2006 el 34.8\% del PBI. Sin embargo, hay que destacar que es uno de los países más proteccionistas de la OMC, especialmente en lo que se refiere a productos agroalimentarios y de consumo, como lo indica el número de procesos de solución de diferen- cias de los que es parte en dicha organización, debido a la existencia de numerosas reglamentaciones internas sobre registros, estándares, certificaciones, requisitos fitosanitarios, que constituyen un auténtico grupo de barreras no arancelarias. Además, Corea es un exportador agresivo, como lo muestra también el número de procedimientos antidumping y antisubvención abiertos contra productos coreanos en otros países y bloques comerciales.

Cuadro N. $^{\circ}$ 5. Ranking de los diez principales productos exportados (millones de US\$ del 2002).

\begin{tabular}{llrrr}
\hline NANDINA & \multicolumn{1}{c}{ Descripción } & Dic. 2006 & Dic. 2007 & Var\% \\
\hline 7108120000 & Oro en las demás formas en bruto & 157.0 & 192.5 & 22.6 \\
2603000000 & Minerales de cobre y sus concentrados & 121.8 & 145.5 & 19.5 \\
2301201100 & Harina de pescado sin desgrasar con contenido de & 56.3 & 66 & 17.2 \\
& grasa $>2 \%$ & & & \\
7403110000 & Cátodos y secciones de cátodos de cobre refinado & 77.8 & 52.7 & -32.3 \\
2608000000 & Minerales de zinc y sus concentrados & 52.0 & 47.8 & -8.1 \\
2710111900 & Los demás aceites pesados o fueloils & 29.5 & 40.3 & 36.3 \\
804502000 & Mangos y mangostanes, frescos o secos & 9.8 & 20.7 & 111.2 \\
709200000 & Espárragos, frescos o refrigerados & 19.0 & 20.7 & 8.7 \\
901119000 & Café sin descafeinar, sin tostar & 25.4 & 19.4 & -23.5 \\
7106911000 & Plata en bruto sin alear & 17.2 & 18.4 & 7.0 \\
\hline
\end{tabular}

Fuente: SUNAT

Elaboración: MINCETUR

Cuadro N. ${ }^{\circ}$ 6. Corea: Evolución del consumo Variación Porcentual.

\begin{tabular}{|c|c|c|c|c|c|c|c|c|c|c|}
\hline & \multicolumn{2}{|l|}{2005} & \multicolumn{3}{|c|}{2006} & \multicolumn{5}{|c|}{2006} \\
\hline & Anual & Anual & Nov. & $\begin{array}{c}\text { Trim. } \\
3\end{array}$ & $\begin{array}{c}\text { Trim. } \\
4\end{array}$ & $\begin{array}{c}\text { Trim. } \\
1\end{array}$ & $\begin{array}{c}\text { Trim. } \\
2\end{array}$ & $\begin{array}{c}\text { Trim. } \\
3\end{array}$ & Oct. ${ }^{1}$ & Nov. ${ }^{1}$ \\
\hline Bienes de Consumo & 4.1 & 4.7 & 5.1 & 2.9 & 4.5 & 7.1 & 5.3 & 8.6 & 8.4 & 5.9 \\
\hline (Ajustado por estacionalidad) $^{2}$ & - & - & 0.6 & -0.2 & 3.0 & 2.5 & -0.2 & 3.3 & -0.9 & -1.2 \\
\hline a. Bienes Duraderos ${ }^{/ 3}$ & 6.5 & 11.0 & 11.8 & 11.4 & 9.6 & 17.0 & 14.1 & 14.6 & 21.9 & 10.0 \\
\hline a.1. Automóviles & 9.5 & 8.1 & 1.5 & 4.2 & 1.3 & 9.8 & 9.3 & 4.3 & 12.8 & -3.4 \\
\hline b. Bienes semi duraderos ${ }^{14}$ & 7.9 & 5.1 & 6.8 & 2.9 & 3.6 & 6.4 & 3.6 & 5.7 & 7.7 & 7.4 \\
\hline c. Bienes no duraderos ${ }^{/ 5}$ & 1.2 & 1.1 & 0.3 & -1.7 & 2.0 & 2.1 & 0.9 & 6.3 & 1.1 & 2.3 \\
\hline
\end{tabular}

/1 Datos Preliminares.

/2 Cambio porcentual respecto al periodo anterior

/3 Bienes duraderos (25.4\%): Automóviles, aparatos electrónicos, equipos de comunicación, etc.

/4 Bienes semi-duraderos (24.0\%): Vestido y calzado

/5 Bienes no duraderos (50.5\%): Alimentos, medicinas, cosméticos, combustible, tabaco, etc. 


\section{Principales socios comerciales.}

China es el principal socio comercial de Corea ocupando el primer lugar como cliente y, desde el año 2007, como proveedor. Este parece ser el resultado de una tendencia estructural que hace a la economía coreana cada vez más dependiente del mercado chino, debido a la gran expansión de la demanda interna en dicho país, la proximidad geográfica y el proceso de deslocalización de la producción coreana hacia China que las empresas coreanas están llevando a cabo en los últimos años (ver Gráfico $\mathrm{N}^{\circ}$ 10).También figuran Japón y Estados Unidos, aunque ambos han ido cediendo cuota de mercado a China en los últimos años. Entre los tres países supusieron el $42.4 \%$ del total de las exportaciones coreanas y el $44.3 \%$ de las importaciones en 2006. En cuarto lugar se sitúa la UE, como bloque, aunque individualmente sólo Alemania ocupa una posición destacada.

\section{Principales proveedores.}

Hasta el 2006 Japón ha venido siendo el principal proveedor de Corea del Sur; sin embargo, su cuota de importaciones coreanas se ha ido reduciendo a medida que crecía la de China, de forma que los datos para los ocho primeros meses de 2007 muestran ya a este país como primer proveedor, con una cuota del $17.61 \%$ (19.6\% en el 2004), mientras que la de Japón queda en el $16.04 \%$ (20.5\% en 2004) (ver Cuadro $\left.\mathrm{N} .{ }^{\circ} 7\right)$. Este fenómeno es tanto reflejo de la creciente actividad exportadora china como resultado de la deslocalización de la producción
Gráfico N. ${ }^{\circ}$ 10. Consumer Goods Sales.

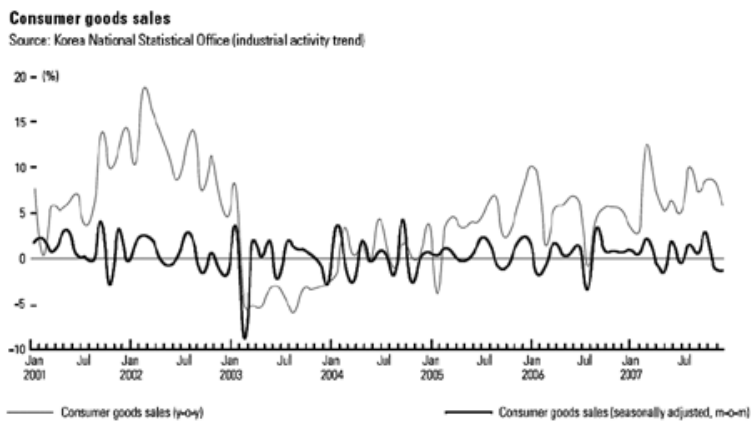

de empresas coreanas hacia China. En cualquier caso hay que señalar que Japón sigue siendo, junto con Alemania y los exportadores de petróleo, uno de los pocos países que mantienen superávit comercial con Corea. Al igual que en el caso de su situación como cliente, Estados Unidos también está perdiendo peso relativo como suministrador de Corea.

En el 2003, el 13.88\% del total de las importaciones coreanas procedían de los Estados Unidos; sin embargo, en el 2006 este porcentaje se redujo a $10.85 \%$, manteniéndose casi sin variación (10.88\%) en los ocho primeros meses del 2007. Las importaciones de la UE tomada en conjunto colocarían a ésta como cuarto proveedor, con una cuota muy similar a la de Estados Unidos. Individualmente Alemania es, con gran diferencia, el mayor exportador comunitario y el único que ocupa una posición destacada, sexto en 2006 y quinto en el 2007. Por último, hay que señalar que la dependencia del exterior para el abastecimiento energético hace que países productores de petróleo como Arabia Saudita

Cuadro $\mathbf{N}^{\circ}{ }^{7}$. Principales países proveedores de Corea del Sur (datos en millones de US\$).

\begin{tabular}{|c|c|c|c|c|c|c|c|c|}
\hline Países & 2004 & $\%$ & 2005 & $\%$ & 2006 & $\%$ & $\begin{array}{c}2007 \\
\text { (ene - ago) } \\
\%\end{array}$ & $\%$ \\
\hline Japón & $46,144.00$ & 20.56 & $48,403.00$ & 18.53 & 51.93 & 16.78 & $36,714.00$ & 16.04 \\
\hline China & $29,585.00$ & 13.18 & $38,648.00$ & 17.79 & $48,557.00$ & 15.69 & $40,310.00$ & 17.61 \\
\hline Estados Unidos & $28,783.00$ & 12.82 & 11.80 & 11.40 & 9.60 & 17.00 & 14.10 & 14.60 \\
\hline Arabia Saudita & $11,800.00$ & 5.26 & $16,106.00$ & 6.17 & $20,552.00$ & 6.64 & $13,320.00$ & 5.82 \\
\hline Emiratos Árabes Unidos & $7,290.00$ & 3.25 & 10.02 & 3.83 & $12,931.00$ & 4.18 & $7,776.00$ & 3.40 \\
\hline Alemania & $8,486.00$ & 378.00 & $9,774.00$ & 374.00 & $11,365.00$ & 3.67 & $8,718.00$ & 3.81 \\
\hline Australia & $7,438.00$ & 3.31 & $9,859.00$ & 3.77 & $11,309.00$ & 3.66 & $8,398.00$ & 3.67 \\
\hline Taiwán & $7,312.00$ & 3.26 & $8,050.00$ & 3.08 & $9,287.00$ & 3.00 & $6,306.00$ & 2.76 \\
\hline Indonesia & $6,368.00$ & 2.84 & $8,184.00$ & 3.13 & $8,848.00$ & 2.86 & $5,660.00$ & 2.47 \\
\hline
\end{tabular}


y Emiratos Árabes Unidos e Indonesia se sitúen entre los principales países proveedores.

En la Balanza Comercial Coreana destaca el aumento de las importaciones, provocado principalmente por los aumentos de los precios del crudo; mientras tanto el superávit comercial se redujo de US\$ 16.08 millones en 2006 a US\$ 15.07 millones en el 2007 (ver Cuadro N. ${ }^{\circ}$ 8).

Corea es un país fuertemente dependiente de la importación de materias primas, especialmente petróleo y combustibles, que supusieron un 28.03\% de sus importaciones en el 2006. Esto lo hace muy vulnerable a las variaciones de precios en los mercados internacionales, exponiéndole a choques de oferta. Las importaciones en el 2007 aumentaron en 15.3\% respecto del año anterior, considerando un monto total de US\$ 356.69. Los precios de las materias primas (hasta $16.0 \%$ ), bienes de capital (hasta $14.2 \%$ ) y bienes de consumo (un 17.8\%), se dispararon impulsados principalmente por la continuación del alza de precios de las materias primas incluido el petróleo crudo, y la recuperación de la demanda interna. En diciembre, las importaciones registraron US\$ 34.11 millones hasta $24.0 \%$ de año en año, debido al aumento de las importaciones de materias primas como el petróleo crudo (hasta $40.1 \%$ ) y gas natural licuado (hasta $49.6 \%$ ), a raíz del aumento de los precios del petróleo.

El sector de la electrónica y telecomunicaciones, al mismo tiempo que es el principal sector exportador (26.29\% del total en 2006), también es una de las principales fuentes de demanda de importaciones, especialmente de componentes para su incorporación a los productos de exportación (17.01\% del total en 2006). Otro sector a destacar es el de maquinaria mecánica y equipos de precisión, cuya situación es similar a la del sector de la electrónica. Es el tercer capítulo en importaciones, con una cuota del $10.43 \%$ sobre el total y el tercero en exportaciones con 13\%. El principal suministrador de estos productos, en especial de los que requieren alta tecnología, es Japón seguido por Alemania y Estados Unidos.

A pesar de tener una importante industria siderúrgica local, la fuerte demanda de estos productos por parte de los sectores automotrizy construcción naval hace que Corea deba recurrir a los mercados exteriores para su abastecimiento. El capítulo de productos siderúrgicos se sitúa en el cuarto lugar del ranking de importaciones, suponiendo un $5.46 \%$ del total en el 2006 y un $6.48 \%$ en el primer trimestre del 2007. El capítulo de óptica y fotografía ocupa el quinto lugar, con una cuota por debajo del 5\% incluyendo productos de consumo, pero también una buena cantidad de componentes para incorporar a los productos de exportación. Posteriormente se sitúan los capítulos de productos químicos orgánicos y plásticos así como sus manufacturas, que entre ambos suman cerca del 5\% del total de importaciones (ver Cuadro N. ${ }^{\circ}$ ).

\section{CONCLUSIONES}

1. El Foro de Cooperación Económica Asia-Pacífico (APEC) representa un bloque económico atractivo tanto para la economía coreana como para la economía peruana, posibilitando a esta última un intercambio comercial con las economías de este bloque por US\$ $38,757.8$ millones, equivalente al 55\% del comercio total peruano.

2. Aunque para el Perú el país de destino de Corea del Sur no sea uno de sus principales socios comerciales, sin embargo representa el tercer país asiático de mayor preponderancia en el comercio internacional, después de China y Japón. Para el Perú, entre el 2006 y 2007, se ha presen-

Cuadro N. ${ }^{\circ}$ 8. Balanza Comercial de Corea del Sur. En miles de millones de US\$.

\begin{tabular}{lrrrrrrrr}
\hline & \multicolumn{4}{c}{2006} & \multicolumn{5}{c}{2007} \\
\cline { 2 - 10 } & \multicolumn{1}{c}{ Oct. } & \multicolumn{1}{c}{ Nov. } & \multicolumn{1}{c}{ Dic. } & Ene - Dic. & Oct. & Nov. & Dic. & Ene - Dic. \\
\hline Exportaciones & 28.02 & 30.60 & 27.78 & 325.46 & 34.44 & 35.84 & 33.25 & 371.76 \\
Variación \% anual & 10.50 & 18.50 & 12.30 & 14.40 & 22.90 & 17.10 & 15.50 & 14.20 \\
Importaciones & 25.62 & 26.77 & 27.52 & 309.38 & 32.65 & 33.71 & 34.11 & 356.69 \\
Variación \% anual & 13.10 & 12.20 & 13.80 & 18.40 & 27.40 & 25.90 & 24.00 & 15.30 \\
Balanza Comercial & 2.39 & 3.84 & 1.26 & 16.08 & 1.79 & 2.13 & -0.87 & 15.07 \\
\hline
\end{tabular}


tado una variación del $81 \%$ en las exportaciones peruanas dirigidas hacia dicho mercado, lo cual constituye una importante oportunidad.

3. Entre los principales productos exportables del Perú encontramos al oro, cátodos y secciones de cátodos de cobre refinado, aceites pesados ofuel oils, espárragos frescos o refrigerados, polos de algodón para hombre o mujer y plata sin alear; mientras que Corea del Sur es un país netamente dependiente de la importación de materias primas, especialmente petróleo y combustibles.

4. Para el período 2007, en el mercado coreano, los precios de las materias primas, bienes de capital y bienes de consumo aumentaron en $16.0 \%, 14.2 \%$ y $17.8 \%$, respectivamente, principalmente impulsadas por la continuación de alza de precios de las materias primas incluido el petróleo crudo y la recuperación de la demanda interna, representando una oportunidad para la exportación de materia prima peruana a dicho destino.

\section{PÁGINAS WEB}

APEC PERU 2008: http://www.apec2008.org.pe/contenidospanish/apecqueesapec.html
Banco Central de Reserva del Perú - Guía Metodológica de la Nota Semanal: http://www.bcrp. gob.pe/bcr/dmdocuments/Publicaciones/guiam/ Balanza_Comercial.pdf

Biblioteca Virtual: http://www.eumed.net/cursecon/ libreria/cl-mm-macro/21.htm

Diario El Comercio: http://www.elcomercioperu.com.pe/ http://www.exportservices.be/korea.htm http://travel.state.gov/travel/cis_pa_tw/cis/ cis_1018.html

Instituto Nacional de Estadística e Informática: http://www.inei.gob.pe

https://www.cia.gov/library/publications/the-worldfactbook/geos/ks.html

Korea International Trade Association: http://www.kita.net/

Ministerio de Comercio Exterior y Turismo (MINCETUR): http://www.mincetur.gob.pe/apec/index.asp?cont $=52744$

Superintendencia Nacional de Administración Tributaria (SUNAT ADUANAS): http://www. aduanet.gob.pe

United States Department of Housing and Urban Development: http://www.hud.gov/offices/ fheo/lending/subprime.cfm

Cuadro № 9. Principales productos importados - Corea del Sur Capítulos arancelarios de la Nomenclatura Combinada de la UE) (Datos en millones de US\$)

\begin{tabular}{|c|c|c|c|c|c|c|c|c|}
\hline Importaciones & 2004 & $\%$ & 2005 & $\%$ & 2006 & $\%$ & $\begin{array}{c}2007 \\
\text { (ene -ago) }\end{array}$ & $\%$ \\
\hline $\begin{array}{l}\text { Combustibles minerales, aceites } \\
\text { minerales y productos de su } \\
\text { destilación }\end{array}$ & $50,331.00$ & 22.42 & $67,556.00$ & 25.86 & $86,717.00$ & 28.03 & $59,529.00$ & 26.01 \\
\hline $\begin{array}{l}\text { Máquinas, aparatos y material } \\
\text { eléctrico }\end{array}$ & $45,464.00$ & 20.25 & $48,734.00$ & 18.66 & $52,622.00$ & 17.01 & $37,561.00$ & 16.41 \\
\hline $\begin{array}{l}\text { Reactores nucleares, calderas, } \\
\text { máquinas, aparatos y artefactos } \\
\text { mecánicos }\end{array}$ & $24,045.00$ & 11.07 & $27,970.00$ & 10.71 & $32,259.00$ & 10.43 & $26,069.00$ & 11.39 \\
\hline Fundición, hierro y acero & $14,084.00$ & 6.27 & $16,360.00$ & 6.26 & $16,892.00$ & 5.46 & $15,198.00$ & 6.64 \\
\hline $\begin{array}{l}\text { Instrumentos y aparatos de ópti- } \\
\text { ca, fotografía o cinematografía }\end{array}$ & $10,819.00$ & 4.82 & $12,879.00$ & 4.93 & $13,991.00$ & 4.52 & $7,693.00$ & 3.36 \\
\hline Productos químicos orgánicos & $7,212.00$ & 3.21 & $8,477.00$ & 3.24 & $8,810.00$ & 2.85 & $6,418.00$ & 2.80 \\
\hline $\begin{array}{l}\text { Metales metalíferos, escorias y } \\
\text { cenizas }\end{array}$ & $3,498.00$ & 1.56 & $5,194.00$ & 1.99 & $8,168.00$ & 2.64 & $6,143.00$ & 2.68 \\
\hline Plástico y sus manufacturas & $4,399.00$ & 1.96 & $5,401.00$ & 2.07 & $6,089.00$ & 1.97 & $4,430.00$ & 1.94 \\
\hline
\end{tabular}

Fuente: Korea Internacional Trade Association (www.kita.net) 